\title{
Caio F: consciência de si, consciência do outro
}

Márcia Ivana de Lima e Silva | UFRGS

Resumo: O presente trabalho analisa o processo de criação do conto "Creme de alface", de Caio Fernando Abreu, através das quatro versóes existentes em seu Arquivo Documental, doado ao Instituto de Letras da UFRGS. O estudo genético tem como instrumentalização teórica a confluência das teses de Mikhail Bakhtin sobre a linguagem e de Theodor Adorno sobre a inserção social da obra lírica. É hipótese deste estudo que tais teorias ajudam a explicar o processo criativo deste escritor, porque as rasuras estão ligadas às suas intençôes compositivas e ideológicas.

Palavras-chave: Caio Fernando Abreu, Critica Genética, Bakbtin e Adorno.

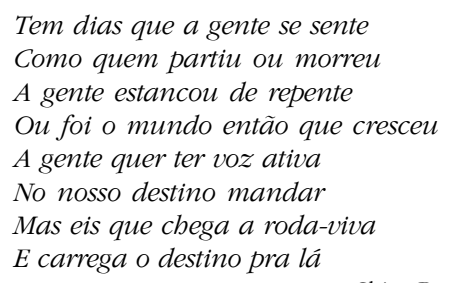

\footnotetext{
A discussão sobre o caráter nacional da literatura brasileira e sua conseqüente inserção social é já matéria de preocupação dos estudos literários
} 
desde meados do século XIX, tomando fôlego no início do século XX, quando os primeiros historiadores se debruçaram sobre a produção literária brasileira, organizaram-na, classificaram-na e tentaram entendê-la. Antonio Candido defende que nossos escritores românticos estavam convencidos de que sua tarefa era muito maior do que escrever textos literários; acreditavam que, ao construírem sua obra, eles igualmente construíam a nação. A idéia de nação não é apenas tema em suas obras, mas ponto de partida e de chegada.

Num salto temporal arbitrário, mas significativo, poderíamos pensar na literatura modernista e entender seu esforço de também construir uma nação. As bases são outras, pois há a produção anterior que cobra um posicionamento. Quero dizer que o nacionalismo crítico dos modernistas contrapõe-se ao nacionalismo ufanista dos românticos, não apenas no que diz respeito à noção de arte, mas, talvez principalmente, à noção de nação. A partir de uma nação já constituída, tarefa cumprida pelos românticos, os modernistas podem (e devem) repensar tal constituição e sugerir os "ajustes" para que seja autêntica, seja, enfim, "diferente".

A partir dos modernistas, o campo está aberto para a manifestação da diferença, da individualidade, da subjetividade, escapando, assim, de um alinhamento homogêneo de nossa produção literária. Colaboram para isso as vanguardas européias, a consolidação dos ensinamentos psicanalíticos de Sigmund Freud, os experimentalismos literários de James Joyce e Virginia Woolf, bem como o clima de ensimesmamento decorrente da experiência nas duas Grandes Guerras, colocando em cheque a noção de nacionalismo e o modelo de sociedade. É quando a prosa intimista ganha espaço, acentuando a necessidade de o homem pensar o mundo que o cerca a partir de si mesmo. É quando as fronteiras facilmente demarcadas de outrora cedem e deixam à mostra o entre-lugar, a intersecção, tanto dos sujeitos quanto dos textos literários.

Theodor Adorno, falando sobre a lírica, diz que:

em todo poema lírico a relação histórica do sujeito à objetividade, do indivíduo à sociedade, precisa ter encontrado sua materialização no elemento do espírito subjetivo, reverberado sobre si mesmo. Essa sedimentação será tanto mais perfeita quanto menos a formação lírica tematizar a relação entre eu e sociedade, quanto mais involuntariamente cristalizar-se essa relação, a partir de si mesma, no poema.

1. ADORNO, 1983, p. 197. 
Mais adiante nesse mesmo ensaio, o filósofo acrescenta que o meio para que tal subjetividade torne-se objetiva é a linguagem, que funciona como um elo entre lírica e sociedade. Ou seja, não há como pensar a representação social do poema fora da esfera da subjetividade, já que somente o indivíduo realmente mergulhado na linguagem conseguirá concretizar a relação entre o conteúdo lírico e a vida social. Incluo em tais reflexões a prosa poética, sua inserção subjetiva e seu refinamento com o trabalho da linguagem.

Ao lado de tais reflexões, aproximo as considerações de Mikhail Bakhtin, para quem a palavra é o material privilegiado da consciência; é através dela que o homem elabora sua concepção de mundo, seu entendimento de si mesmo e dos outros. Como "a consciência individual é um fato sócio-ideológico", qualquer elaboração discursiva é, ao mesmo tempo, individual e social. A teoria de Bakhtin tem como elemento central a palavra, em termos sociais, pois o que vale é a sua capacidade comunicativa e a sua intencionalidade. Por estar sempre direcionada ao outro, ela é dialógica, comportando concomitantemente o discurso de quem a produz e o discurso de quem a recebe. A produção de um enunciado, por sua vez, implica a absorção de muitos outros enunciados, controlados por condições sociais denunciadoras de uma visão de mundo. Ao redimensionar a importância da linguagem no processo social, Bakhtin cria um modelo teórico em que o discurso é o elemento central, porque a própria sociedade não é separável da linguagem.

Para pensar a criação literária com base nesses dois postulados, há que se levar em conta o fato de que, durante o trabalho criativo, operam mecanismos pessoais e coletivos, com os quais o autor cria um discurso em que aparecem a palavra do eu e a do outro, colocando a nu as relações pessoais e sociais através das marcas lingüísticas e revelando sua mais íntima condição existencial.

Essas brevíssimas reflexões iniciais servem de ponto de partida para incluir a produção de Caio Fernando Abreu na discussão sobre subjetividade e sociedade, sem separá-las, porque acredito que mesmo o texto literário mais subjetivo, mais intimista, carrega em si uma marca social, por revelar, no mínimo, uma tensão existencial do sujeito na sociedade.

Caio F, como gostava de assinar, nasceu a 12 de setembro de 1948, em Santiago do Boqueirão, RS, e morreu em fevereiro de 1996, em Porto Alegre. Sua obra está filiada à "narrativa introspectiva", tendo ele como "mentoras" Clarice Lispector, Lygia Fagundes Telles, Hilda Hilst, para citar apenas alguns nomes

2. BAKHTIN, 1988, p. 35 . 
brasileiros. Pensar a produção de Caio F como prosa poética poderia significar a total exclusão da perspectiva de sua representatividade social. No entanto, é justamente pelo intenso mergulho na individualidade de suas personagens que seus textos atingem um grau elevado de vínculo com as questões sociais que cercam esses sujeitos. A sugestão é que, ao contrário do que normalmente se pensa, a narrativa intimista tem igualmente sua inserção social assegurada, já que o sujeito representado carrega as marcas da família em que foi criado, do grupo social a que pertence e, conseqüentemente, de suas raízes, crenças e valores. $O$ próprio Caio assim se manifesta em correspondência a José Márcio Penido, datada de 02/11/1990, quando do lançamento do romance Onde andará Dulce Veiga?:

(...) Mas vamos lá, tudo por Dulce veiga. Divulgue ele(a), sinto que é como se fosse meu primeiro livro, no sentido de que me desembaracei do umbigo e cheguei mais perto da ficção, do Brasil, do humano alheio, não apenas meu. ${ }^{3}$

É como se o autor de Morangos mofados percebesse o deslocamento da discussão do caráter social da literatura para o âmbito da representação do sujeito, fazendo-a deslizar da caracterização topográfica para a da subjetividade. $O$ foco recai sobre os dilemas da alma humana, independentemente do lugar onde mora o sujeito ou a que grupo social pertence, passando, pois, a ser ele a figura central da representação.

É a partir de tal proposta que pretendo verificar as quatro versões do conto "Creme de alface", de Caio Fernando Abreu, publicado no livro Ovelhas negras, de 1995.

A primeira versão apresenta 3 páginas datiloscritas com rasuras à caneta BIC azul. A segunda versão também é datiloscrita, mas tem 4 páginas, com poucas rasuras à caneta BIC azul. As rasuras são mais de caráter estilístico, sem alterações substanciais de conteúdo. É datada ao final: 1977.

A terceira versão nos reserva a maior quantidade de rastros do processo de criação. São 3 páginas repletas de rasuras tanto estilísticas quanto de conteúdo. Ou seja, há efetivamente uma mudança no conto, seja pelo aumento da complexidade da personagem, seja pela ampliação do enredo. As rasuras são igualmente à caneta BIC azul, e a página final também apresenta o ano de 1977,

3. ABREU, 2002, p. 193. 
escrito a mão. A quarta e última versão acata os acréscimos propostos na versão anterior, mas ainda apresenta mais alterações, o que aumenta o número de páginas para 6. O conto é escrito em máquina elétrica, com rasuras à caneta hidrocor preta, sem datação.

Nesta quarta versão, o conto está dividido em três partes, marcadas por numeração romana, ampliando a divisão que já aparecia nas outras versões, cuja estratégia era apenas o espaçamento maior. A numeração aponta para a separação dos segmentos da ação do conto, a saber, a chegada à bilheteria do cinema, o confronto com a menina e a entrada na sala de cinema para assistir o filme.

Começo ressaltando o fato de que o narrador está totalmente ligado ao ponto de vista da personagem adulta, mas assume um tom "neutro", melhor dizendo, amoral, em relação às suas atitudes. O que sobressai é o embate social que se transforma em embate pessoal. A pequena pedinte não pára de pedir "um dinheirinho/troquinho" com sua ladainha de misérias na família, enquanto a moça, por sua vez, não quer lhe dar esmola. Há o confronto físico, ganho pela adulta, o que marca sua superioridade em todos os aspectos: físico, social e, principalmente, pessoal. Aqui aparece a ampliação do embate entre as duas, descrito como se fosse uma dança, ao mesmo tempo em que coloca a menina em posição de animal através de duas palavras: "cachorro", que aparece em todas as versões, e "bicho", na quarta versão.

O que sobressai neste conto é a falta de consciência social da personagem, a qual só se acentua através das rasuras, a ponto de o conto fechar com a frase: "eu mereço, danem-se os crediários, custe o que custar, saindo daqui vou comprar imediatamente um bom creme de alface" (versão 4), que havia começado com "- Preciso imediatamente comprar um creme de alface." (v.1 e v.2), e ainda: "Saindo daqui, preciso, preciso imediatamente comprar um creme de alface." (v.3).

Caio Fernando Abreu amplia o contraste entre aparência e essência através das rasuras, até porque a parte I do conto mostra a vida da personagem, cujos familiares são doentes, viciados em droga, um alcoólatra, um suicida, uma mãe solteira. Já na versão 1 aparecem esses problemas familiares, mas é na versão 3, que são detalhados, reforçando o contraste com a possibilidade de a pedinte estar mentindo. Além disso, na versão 4, aparece uma frase emblemática para o entendimento do conto: "já cansei de dizer que mendigo é problema social, não pessoal", no sentido de entender a caracterização da personagem, oposta ao que normalmente Caio expressa em sua obra: existir é um problema social. 
A personagem foge de pensar sobre si mesma, sobre sua condição existencial e social, e amplia tal fuga ao bater na menina. Sua preocupação com a aparência supera qualquer questionamento social mais profundo. Uma outra marca deste afastamento do eu é a eliminação na versão 3 de dois versos de um poema de Florbela Espanca que apareciam nas versões 1 e 2: "sempre da vida - o mesmo estranho mal / e o coração - a mesma chaga aberta”. Não sobra espaço para o lirismo que apontaria para um aprofundamento, inicialmente, existencial.

Nesse sentido, ao organizar as falas e pensamentos das personagens, com inserções e eliminações, Caio F marca o posicionamento sócio-ideológico de cada uma delas, construindo um universo que se integra àquele por ele vivenciado, a saber, o Brasil do final da década de 70 (1977). Disso resulta a percepção das forças internas e externas que controlam o ser humano e suas ações. Imagino que Caio queira despertar nossa consciência social, justamente através da ausência desta na personagem. O que fica é que a falta de consciência de si leva à incapacidade de ver o outro. É o que ocorre com a personagem que não existe, que é tão essencial quanto um creme de alface.

Abstract: This work analises the criative process of Caio Fernando Abreu's shortstory "Creme de alface", including the four versions that are in his Documental Archive, at Instituto de Letras from UFRGS. The genetic study is based on the theories of Mikhail Bkhtin and Theodor Adorno, in order to explain his intentions during the writing process.

Key words: Caio Fernando Abreu, Genetic Critic, Bakhtin and Adorno..

\section{Referências Bibliográficas}

ABREU, Caio Fernando. Ovelhas negras. Porto Alegre: Sulina, 1995.

ABREU, Caio Fernando. Cartas. Org. Ítalo Moriconi. Rio de Janeiro: Aeroplano, 2002.

ADORNO, Theodor. Lírica e sociedade. In: BENJAMIN, Walter et al. Textos escolbidos. Trad. José Lino Grünnewald et al. São Paulo: Abril Cultural, 1983. (Col. Os pensadores). BAKHTIN, Mikhail. Marxismo e filosofia da linguagem. 4. ed. Trad. Michel Laud e Yara Frateschi Vieira. São Paulo: HUCITEC, 1988.

CANDIDO, Antonio. Formação da literatura brasileira: momentos decisivos. 6. ed. Belo Horizonte: Itatiaia, 1981. 